\title{
EFEITO DE ADESIVOS PARA PRÓTESE TOTAL NA COLONIZAÇÃO CANDIDA ALBICANS
}

\section{Monique Stefane Cordeiro de Souza ${ }^{1}$; Mário Cezar Silva de Oliveira ${ }^{2}$; Morgana Kelly de Souza Santos ${ }^{3}$}

\author{
${ }^{1}$ Bolsista PIBIC/Cnpq, Graduanda em Odontologia, Universidade Estadual de Feira de Santana, email: \\ monicsouza@hotmail.com \\ ${ }^{2}$ Orientador, Departamento de Saúde, Universidade Estadual de Feira de Santana, email: mcezar11@ gmail.com \\ ${ }^{3}$ Participante do projeto, bolsista PROBIC/Uefs, Graduanda em Odontologia, email: morgakelly@ hotmail.com
}

Palavras-chave: materiais biocompatíveis, cândida, prótese total

\section{INTRODUÇÃO}

Os adesivos são produtos utilizados para favorecer a fixação entre a prótese total e a mucosa. Compostos geralmente por um agente de adesão, o polissacarídeo sintético, assim como antifúngicos, corantes e estabilizantes (POLIZOYS, 2011). Os adesivos para prótese total são utilizados por indivíduos edêntulos como um coadjuvante útil à retenção e estabilidade da prótese mucossuportada (OLIVEIRA, 2010). Os benefícios da utilização dos adesivos são: aumentar a habilidade mastigatória, aumentar a estabilidade da prótese e diminuir o acúmulo de alimentos na base da prótese (ADISMAN, 2012; OZCAN, 2005). Porém, apesar disso e da grande utilização pelos pacientes esses materiais podem incentivar o uso prolongado de dentaduras desadaptadas (OLIVEIRA, 2010), e pouco se conhece sobre sua influência na microbiota bucal, seu potencial de citotoxidade e se o uso contínuo pode acelerar a reabsorção óssea alveolar e provocar hiperplasia tecidual em pacientes desdentados totais (OZCAN, 2005; KORONIS, 2012). Portanto, o objetivo do presente estudo foi avaliar in vitro o efeito de materiais adesivos para prótese sobre o crescimento Candida albicans.

\section{MATERIAIS E MÉTODOS}

Este estudo analisou três adesivos para prótese disponíveis comercialmente, formulados em creme, pó e tiras: Ultra Corega ${ }^{\circledR}$ creme, Ultra Corega ${ }^{\circledR}$ pó e Ultra Corega ${ }^{\circledR}$ fita adesiva, $0,5 \mathrm{~g}$ de cada adesivo foram diluídos a 1:100 em solução de $\mathrm{NaCl}$ a 0,9\%.

\section{RESULTADOS E DISCUSSÃO}

A amostras de adesivos em creme não obtiveram crescimento bacteriano e apresentaram crescimento de candida albicans, porém, todas as placas semeadas contendo o Ultra Corega ${ }^{\circledR}$ pó e Ultra Corega ${ }^{\circledR}$ fita adesiva apresentaram crescimento bacteriano no meio de cultura. Após 24h de incubação, o adesivo em creme pareceu estimular ligeiramente o crescimento de UFCs de Candida albicans, entretanto, esses efeitos estimuladores não refletiram diretamente nos valores da taxa de crescimento das UFCs (figura 1). Ozkan ${ }^{12}$ (2012), realizou um estudo in vivo, comparando a presença de bactérias e fungos entre pacientes que faziam o uso do adesivo e os que não faziam (controle), onde observou-se um aumento para Estreptococos a-hemolíticos e C. albicans nos pacientes que fizeram o uso do adesivo, porém não houve diferença estatística significantes entre o Controle e o grupo experimental. E isto corrobora com os nossos resultados, que embora tenha sido realizado in vitro, não apresentou crescimento significativo de candida albicans no período de 0 a 3 horas. 


\section{Crescimento de UFCs após $24 \mathrm{~h}$ de incubação}

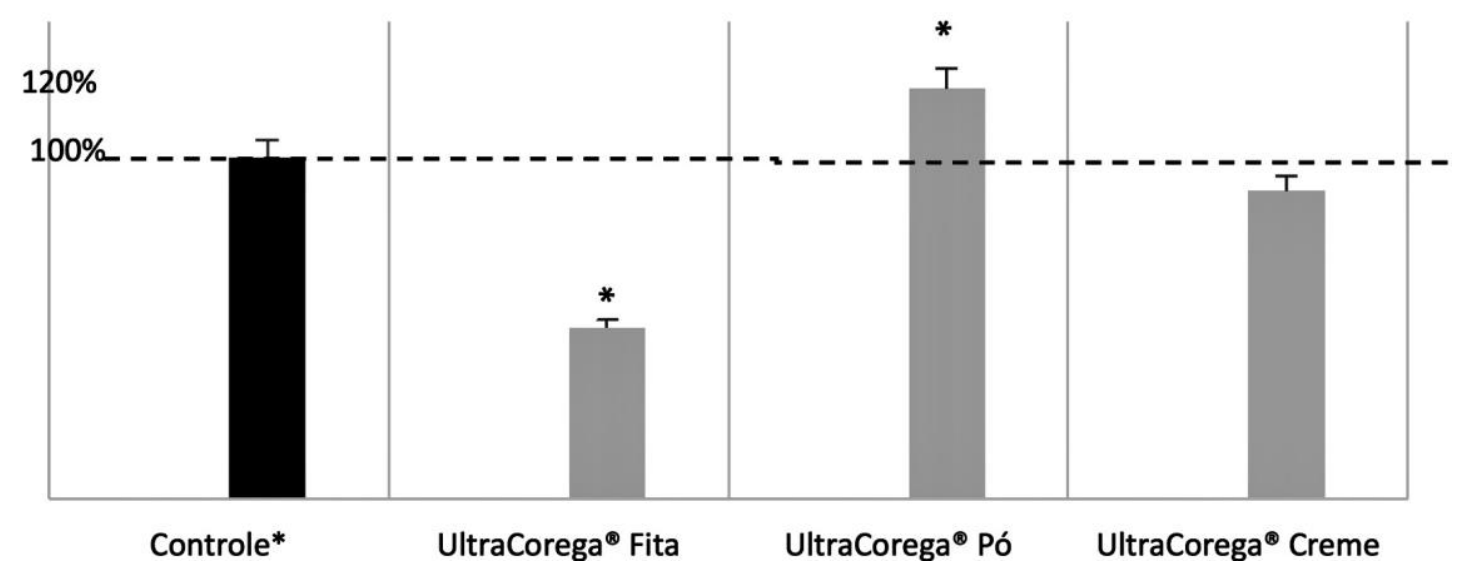

Figura 1 - Efeito dos adesivos sobre o crescimento de C. albicans após 24h de incubação. *Valores com diferenças estatisticamente significantes quando comparados entre si e com o grupo controle $(\mathrm{p}<0,05)$.

\section{CONSIDERAÇÕES FINAIS}

Os adesivos em fita e em pó proporcionaram a formação bacteriana e um efeito inibitório em candida albicans. Verifica-se, então, que os estudos se mostraram controversos de acordo com o tipo de adesivo utilizado.

\section{REFERÊNCIAS}

1. POLYZOIS, G.; LAGOUVARDOS, P., FRANGOU, M., STEFANIOTIS, T. Efficacy of denture adhesives in maxillary dentures using gnathodynamometry: a comparative study. Gerodontology. 2011; 99(2): 155-161.

2. OLIVEIRA, M.C., OLIVEIRA, V.M., VIEIRA, A.C., RAMBOB, I. In vivo assessment of the effect of an adhesive for complete dentures on colonization of Candida species. Gerodontology. 2010; 27(4): 303-307.

3. ADISMAN, I.K. The use of denture adhesives as an aid to denture treatment. J Prosthe Dent. 1989; 62(6): 711-715.

4. OZCAN, M., KULAK, Y., DE BAAT, C., ARIKAN, A., UCANKALE, M. The effect of a new denture adhesive on bite force until denture dislodgement. J Prosthodont 2005; 14(2):122-126.

5. KORONIS, S., PIZATOS, E., POLYZOIS, G., LAGOUVARDOS, P. Clinical evaluation of three denture cushion adhesives by complete denture wearers. Gerodontology. 2012; 29(2):161-169.

6. OZKCAN, Y.K., UÇANKALE, M., OZCAN, M., UNER, N. Effect of denture adhesive on micro-organisms in vivo. Gerodontology 2012; 29(1):9-16. 